\title{
Testing effects of pesticides on macroinvertebrate communities in outdoor stream mesocosms using carbaryl as example test item
}

\author{
Liesa-Kristin Beuter ${ }^{1,2^{*}}$ (D), László Dören ${ }^{2,4}$, Udo Hommen ${ }^{3}$, Matthias Kotthoff ${ }^{3,5}$, Christoph Schäfers ${ }^{3}$
} and Klaus Peter Ebke ${ }^{2}$

\begin{abstract}
Background: In mesocosms, the fate and effects of chemicals can be investigated under more realistic conditions than in laboratory-scale experiments and most mesocosm studies for higher-tier risk assessment are conducted in lentic test systems. However, particularly for the assessment of EPT taxa (Ephemeroptera, Plecoptera, Trichoptera) and gammarids (Amphipoda), which are considered to be ecologically vulnerable macroinvertebrates, lotic systems seem to be more appropriate. Within this pilot study, eight newly constructed stream mesocosms were tested for their suitability in the effect assessment of plant protection products (PPP). By using the insecticide carbaryl as an example test item, five concentrations without replicates were tested under a worst case exposure scenario and three stream mesocosms served as controls.

Results: 15 out of the 51 invertebrate taxa found during the study belonged to EPT taxa, while the common lotic amphipod Gammarus sp. (G. pulex and G. roesili) was the most dominant taxa. Estimation of minimum detectable differences based on mean abundances and variance of taxa in the eight mesocosms before application indicate that for five arthropoda taxa and two non-arthropoda taxa, an analysis of effects would have probably would have been possible in a typical test design for a higher-tier study with more test units. Five of these taxa were typical stream taxa, i.e. mayflies, caddisflies and gammarids. With respect to the effects of carbaryl, multivariate analysis (principal response curve) indicates long-term effects on the macroinvertebrates community over several weeks for the highest carbaryl concentration (120 $\mathrm{mg}$ a.i./L). Potential effects were observed for the amphipod Gammarus sp., the mayfly Ephemera danica and the caddisfly family Limnephilidae.

Conclusions: Through this study it was shown that the stream mesocosms provided suitable habitats for potential sensitive and vulnerable taxa, including those typical for lotic systems. To enable a reliable statistical analysis of the effects within the higher-tier ecological risk assessment, the number of stream mesocosms needs to be enhanced. In addition, colonisation and sampling should be improved to increase the number of taxa with sufficiently high abundances for evaluation.
\end{abstract}

Keywords: Stream mesocosms, Carbaryl, EPT taxa, Lotic ecosystems, Higher-tier risk assessment

*Correspondence: liesa.beuter@mesocosm.de

2 Institut für Gewässerschutz Mesocosm GmbH, Neu-Ulrichstein 5,

35315 Homberg (Ohm), Germany

Full list of author information is available at the end of the article 


\section{Background}

To assess the risk of plant protection products (PPPs) to aquatic non-target organisms, standard single-species tests with, for example, algae, Daphnia sp. and fish are required as the basis of tiered risk assessments [1, 2]. If such laboratory tests indicate a risk, semi-field studies with mesocosms are considered to be a useful highertier tool to investigate the fate and effects of chemicals under more realistic conditions [3]. According to the aquatic guidance document on PPPs for aquatic organisms in edge-of-field surface waters [3], such semi-field studies in artificial ponds, ditches or streams can be used to refine the ecological risk assessments (ERA) on the basis of the ecological threshold option (ETO) and, in contrast to laboratory single-species tests, the ecological recovery option (ERO). With respect to ERO, studies must allow the assessment of effects on and recovery of vulnerable taxa, i.e. sensitive and potentially exposed taxa with a low potential of recovery [4]. Aquatic arthropods with long generation times and of low dispersal ability such as Ephemeroptera, Plecoptera, Trichoptera (EPT) taxa and gammarids (Amphipoda) are considered to be highly vulnerable to some chemical stressors, especially insecticides [4-7]. However, those taxa are more common in lotic than in lentic surface waters $[8,9]$, while the majority of mesocosm studies have been conducted in lentic systems with species more representative of pond or ditch communities [3]. Therefore, lotic test systems are required when taxa preferring running waters are considered to be at risk $[10,11]$. In this case, eight identical stainless steel, outdoor stream mesocosms with a flow length of $10 \mathrm{~m}$ and a maximum water volume of $2500 \mathrm{~L}$ were constructed and colonised with invertebrate sampled in streams close by. Circular flow of water was generated with stainless steel paddle wheels.

The insecticide carbaryl (1-naphthyl- $N$-methylcarbamate) was used as an example test item. This carbamate insecticide is a neurotoxic cholinesterase inhibitor with a short half-life in surface waters and is known to be toxic to aquatic insects and crustaceans [12, 13]. Since 2007, the use of carbaryl has not been allowed in the European Union [14], while it is widely used in the USA [15]. Although several laboratory and semi-field studies for assessing the ecotoxicity of carbaryl to aquatic organisms exist [15-19], only two were conducted in running water systems to assess the risk to stream macroinvertebrate taxa [20,21]. Laboratory studies showed that insects from fast-flow habitats seem to have a particularly high sensitivity to carbaryl exposure ( 96 h-LC $\mathrm{L}_{50}$ : 1.7-17 $\mu \mathrm{g} / \mathrm{L}$; stoneflies and heptageniid mayflies, seven species) [13]. Other reported $96 \mathrm{~h}-\mathrm{LC}_{50}$ values from laboratory bioassays range from 11.1 to $61 \mu \mathrm{g} / \mathrm{L}$ for mayflies, stoneflies and caddisflies [22], with a value of $31 \mu \mathrm{g} / \mathrm{L}$ for
Gammarus fossarum [23]. Therefore, carbaryl was considered a suitable test item for the pilot study.

The main aim of this pilot study was to test if the artificial streams constructed can be used for higher-tier effect assessment of chemicals. In particular, the following questions should be answered:

1. Can populations of potentially sensitive and vulnerable species, characteristic for streams in agricultural landscapes, be established in the test systems?

2. How many and which species can be expected to be sufficiently abundant for effect evaluation?

3. Is there a need to modify the test systems and/or the sampling techniques?

4. Considering the limited number of test systems for this pilot study, does the study provide data which are consistent with the existing data on carbaryl?

\section{Methods}

\section{Test systems}

The study was performed at the test site of the Mesocosm GmbH in Homberg/Ohm (Hessen, Germany, $50^{\circ} 45^{\prime} 9.9^{\prime \prime} \mathrm{N}, 9^{\circ} 1^{\prime} 51.2^{\prime \prime} \mathrm{E}$ ) in eight stainless stream mesocosms with a flow length of $10 \mathrm{~m}$ in a recirculating system. Two guide plates, a flow conditioner, a middle wall and a paddle wheel were installed for assessing reproducible streaming profiles (Fig. 1). The paddle wheels of all eight stream mesocosms were driven by the same single electric motor to ensure the same average flow velocity of $0.11 \mathrm{~m} / \mathrm{s}$ per stream mesocosm. This flow velocity is comparable to the current velocity of small lowland streams in an agricultural landscape (arithmetic mean of selected streams $0.16 \mathrm{~m} / \mathrm{s}$; [24]). Eight weeks before the start of the application of the test item, the stream mesocosms were filled with $63 \mu \mathrm{m}$ sieved pond water, from a natural pond close to the test site, and tap water in a ratio of 2:1 up to a level of $30 \mathrm{~cm}$, which resulted in a water volume of ca. 1300 L. Each stream mesocosm was assembled with four baskets $(6 \mathrm{~L}$ each) with macrophytes planted in sediment and sand. Two of these contained the submerged plant Myriophyllum spicatum and two contained the emergent macrophyte Glyceria maxima. Invertebrates were sampled in two nearby streams (Gleenbach, $50^{\circ} 46^{\prime} 32.0^{\prime \prime} \mathrm{N}, 9^{\circ} 03^{\prime} 20.0^{\prime \prime} \mathrm{E}$ and Pferdsbach, $50^{\circ} 41^{\prime} 50.7^{\prime \prime} \mathrm{N}$, $8^{\circ} 59^{\prime} 58.6^{\prime \prime} \mathrm{E}$ ) by exposing baskets (3 L) filled with stones and leaves of the willow (Salix sp.) for a period of 4 weeks in the water bodies (stream biota trap A; Fig. 1). After this colonisation period, the baskets were taken out of the streams and ten baskets from each stream were transferred directly into each mesocosm. Additionally, two baskets (3 L volume) per stream mesocosm were filled with basalt stones and the macrophyte Ceratophyllum 


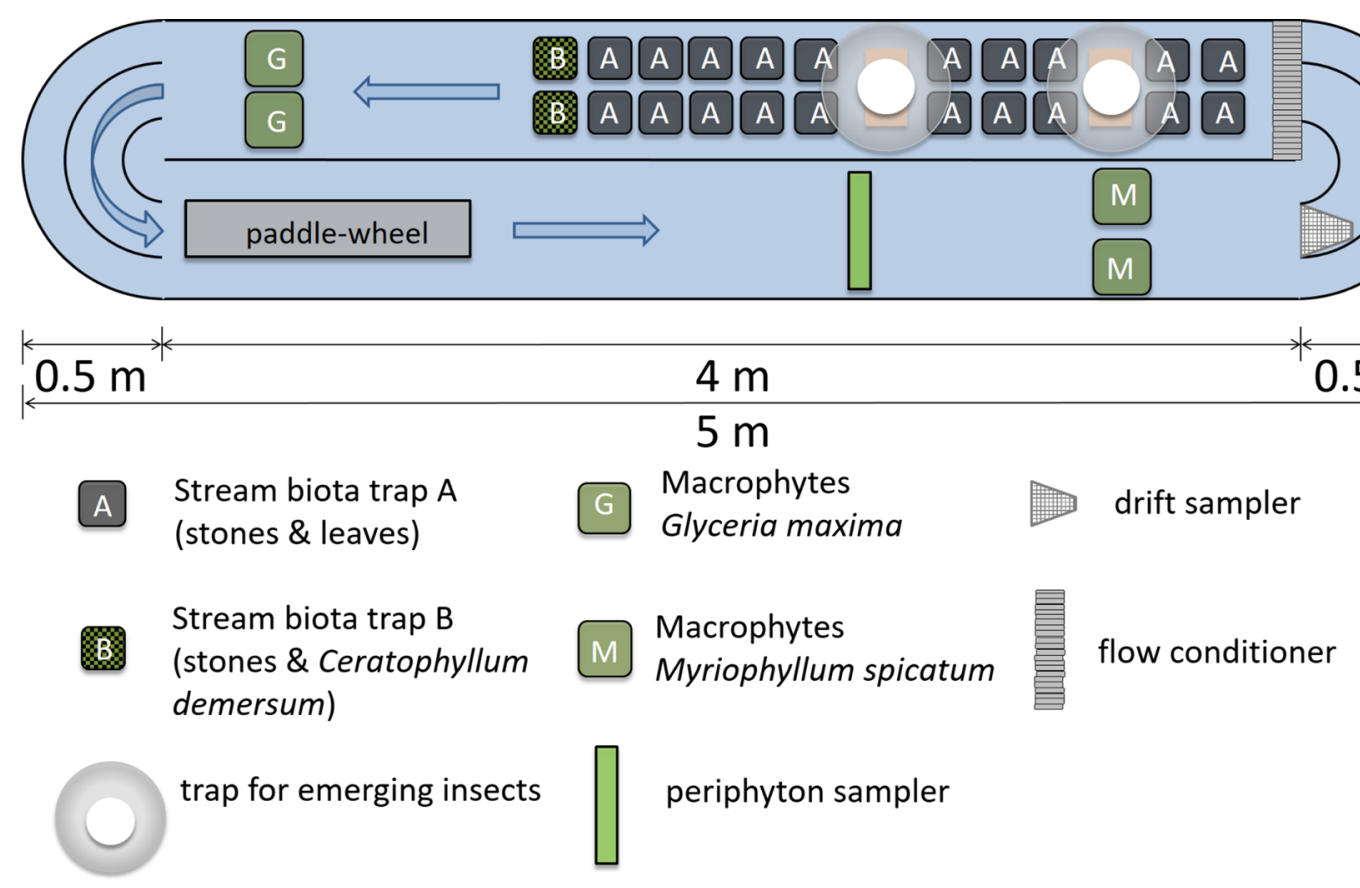

Fig. 1 Experimental setup of one stream mesocosm with different sampling end points

demersum (stream biota trap B; Fig. 1) to provide additional habitat. Zooplankton organisms were not actively transferred to the stream mesocosms, but they may have been introduced via the sieved pond water or the macrophytes. However, the zooplankton community was not investigated within this study, since the focus was on the macroinvertebrates typical of lotic systems. To avoid excessive water temperature and evaporation, a tent for shading was installed four times during the study $(5,9,5$, respectively 6 days depending on the weather conditions, see Additional file 1).

\section{Test item and application}

The test substance carbaryl (CAS No. 63-25-2, Sigma Aldrich) had a purity of $99.9 \%$. Because of low solubility in water $\left(9.1 \mathrm{mg} / \mathrm{L}\right.$ at $\left.20{ }^{\circ} \mathrm{C}[25]\right)$, the stock solution of $240 \mathrm{mg}$ active ingredient (a.i.) in $10 \mathrm{~L}$ deionized water was prepared with $5 \mathrm{~mL}$ acetone as a solvent and $10 \mu \mathrm{L}$ acetic acid for hydrolytic stability. Five carbaryl concentrations $(1.2 ; 3.6 ; 12 ; 36 ; 120 \mu \mathrm{g}$ a.i. carbaryl/L) were tested with one replicate per treatment level. This concentration range was chosen, because it includes the carbaryl $\mathrm{EC}_{50} / \mathrm{LC}_{50}$-values of many species of EPT taxa [13]. Three stream mesocosms served as untreated controls. All treatment levels for the eight stream mesocosms were randomised. Carbaryl was applied once, on 6 August 2015 (day 0) from 11:24 a.m. to 1:30 p.m. The application solution was directly introduced into the water by using funnels, starting with the stream mesocosm with the lowest treatment level and proceeding to the higher levels. Controls were treated with the solvent to ensure the same concentration of acetone in all streams.

\section{Samplings}

Carbaryl concentrations were measured in samples of the application solutions and of the stream mesocosm water taken $1,3,24,48,120$ and $144 \mathrm{~h}$ after application. At least 2 weeks before the application of carbaryl until the end of the study, 8 weeks after application, the following parameters were measured or sampled weekly: macroinvertebrate abundances, emergence of insects, chlorophyll a of periphyton. Drift of invertebrates was monitored 4, 8 and $24 \mathrm{~h}$ after application. Furthermore, physicochemical water parameters such as temperature, $\mathrm{pH}$, oxygen concentration and conductivity were sampled weekly, while phosphate, nitrate, ammonium and water hardness were sampled three times during the study (day 9, 29, 55).

\section{Measurements Carbaryl}

To confirm the intended dosing of the stream mesocosms and to describe the time course of exposure of the organisms, depth-integrated water samples were collected with a stainless steel pipe at three defined locations per stream mesocosm and pooled. The three samples of the untreated controls were pooled for 
analysis. Two subsamples of $10 \mathrm{~mL}$ were taken from each pooled sample for the treated stream mesocosm and the control mesocosms. $10 \mu \mathrm{L}$ formic acid (98$100 \%)$ was added to the subsamples to stabilise them. Subsamples were stored at $<-18{ }^{\circ} \mathrm{C}$ for a batch-wise analysis in the analytical laboratory. After thawing, the samples were centrifuged at $4000 \mathrm{rpm}$ for $10 \mathrm{~min}$, diluted 1:1 with high-performance liquid chromatography (HPLC)-grade methanol (v/v) and directly measured using a Waters Acquity ultra performance liquid chromatography (UPLC) coupled to a XEVO TQ-S MS/MS instrument. As the chromatographic column, a Waters BEH C18 $(100 \times 2.1 \mathrm{~mm}, 1.7 \mu \mathrm{m})$ was used. The column temperature was set to $55^{\circ} \mathrm{C}$, the injection volume was $20 \mu \mathrm{L}$ and the flow rate was $300 \mu \mathrm{L} / \mathrm{min}$. Mobile phase A was $89.9 \%$ water, $10 \%$ methanol and $0.1 \%$ formic acid, and B was methanol with $0.1 \%$ formic acid. The gradient programme was $50 \% / 50 \%$ of $\mathrm{A}$ and $\mathrm{B}$ at the beginning, then ramping $3 \mathrm{~min}$ to $100 \% \mathrm{~B}$ and ramping back to $50 \% / 50 \% \mathrm{~A}$ and $\mathrm{B}$. The retention time of carbaryl was 1.75 min. Carbaryl was detected in multi-reaction monitoring (MRM) with electrospray ionisation positive mode $\left(\mathrm{ESI}^{+}\right)$using argon as collision gas. Captured mass transitions were $\mathrm{m} / \mathrm{z} 202 \rightarrow 145$ as quantifier and $\mathrm{m} / \mathrm{z} 202 \rightarrow 127$ as qualifier. While the cone voltage was fixed at $20 \mathrm{~V}$ for each transition, the collision energy was $10 \mathrm{eV}$ for the quantifier and $25 \mathrm{eV}$ for the qualifier. The analytical method was validated according to SANCO/3029/99 rev. 4 [26]. Five blank mesocosm water samples were spiked at the LOQ (limit of quantification) concentration of $0.15 \mu \mathrm{g} / \mathrm{L}$, five at the $10 \times$ concentration at $1.5 \mu \mathrm{g} / \mathrm{L}$ and two blank samples were processed as regular samples. The samples were evaluated for recovery, specificity and reproducibility. The dissipation half-life period for carbaryl was calculated using the computer-assisted kinetic evaluation application programme (CAKE, Version 3.2, Tessella Technology \& Consulting) assuming first-order kinetics.

\section{Physicochemical water parameters}

Water temperature, dissolved oxygen, $\mathrm{pH}$ and conductivity were measured in situ using WTW measuring probes (Wissenschaftlich-Technische Werkstätten $\mathrm{GmbH}$, Weilheim). Measurements were carried out $0.2 \mathrm{~m}$ beneath the water surface and always at approximately the same time of the day and at the same position in the stream mesocosms. Concentrations of ammonium, nitrate and phosphate, as well as water hardness, were measured in subsamples of the depthintegrated water samples, as described above. Samples were sieved (mesh size $60-70 \mu \mathrm{m}$ ) before they were analysed photometrically using WTW cube tests.

\section{Macroinvertebrates}

For investigating macroinvertebrate abundances, once a week, two of the type A traps (stones and willow leaves) and one of the type B traps (stones and Ceratophyllum demersum) were taken out of each stream mesocosm (Fig. 1). The invertebrates were rinsed with stream water from the substrate into white vessels for identification and counting. Afterwards, the animals were returned to their respective stream mesocosm. While stream biota type B traps were replaced as a whole, only the content of stream biota type A traps (i.e. stones and the rest of the willow leaves), but not the traps themselves were returned to the stream mesocosms. All macroinvertebrates were identified to the lowest possible taxon by eye or by using a stereomicroscope with transmitted light illumination. The numbers of organisms per taxon found in the three traps of a stream mesocosm were added together. By using the total macroinvertebrate counts of all eight stream mesocosms on two pre-sampling dates (day -21 and -2 ) and the counts of all control stream mesocosms on further sampling days, the dominance of taxa was calculated. Additionally, along with classification into the number of generations per year (voltinism), the taxa were classified as a species at risk (SPEAR) or species not at risk due to pesticides, according to Liess and van der Ohe $[27,28]$.

For investigating the acute effect of carbaryl on the drift behaviour of organisms, a drift sampler was used in each stream mesocosm. A fixed net with $1 \mathrm{~mm}$ mesh size was introduced immediately before application between two guide plates, ca. $3 \mathrm{~m}$ behind the paddle wheel (Fig. 1). The height of the net was $50 \mathrm{~cm}$ to ensure that the whole water column was covered. The net was emptied $4 \mathrm{~h}$, $8 \mathrm{~h}$ and $24 \mathrm{~h}$ after application and the collected organisms were fixed in $70 \%$ ethanol. Samples were evaluated using a stereomicroscope with transmitted light illumination and the organisms were taxonomically identified to the lowest possible taxon. Note that not re-introducing sampled animals is intended since drift should result in local removal of animals which would otherwise not be the case in the circular flow system used here.

\section{Emerging insects}

Two emergence traps (stainless steel) with a diameter of ca. $40 \mathrm{~cm}$ were used in each stream mesocosm to assess the emergence of insects. Together, both traps covered a water surface of $0.25 \mathrm{~m}^{2}$. Emergence traps were covered with a rectangular fine mesh, where a sample fixative was settled at the apex of the structure. The traps were settled straight above the macroinvertebrate substrate samplers 
(Fig. 1). Directly underneath the mesh, two wooden sticks protruded out of the water to facilitate the emergence outside of the water. Emerging insects were fixed in $70 \%$ ethanol and the samples were evaluated using a stereomicroscope with transmitted light illumination. Insects were identified to the lowest possible taxon. The data of the two traps per stream mesocosm were pooled.

\section{Periphyton}

Periphyton was collected on glass slides (total surface area per slide: $0.01855 \mathrm{~m}^{2}$ ) that served as artificial substrate. The glass slides were fixed in a retainer on the stream bed (Fig. 1) and on every sampling occasion another slide was taken for analysis. The periphyton was scraped with a razor blade from the glass slide and mixed with tap water. The analysis of the composition of periphyton was performed using a delayed fluorescence (DF) spectrometer to determine chlorophyll a, as $\mu \mathrm{g} / \mathrm{m}^{2}$, and the respective fractions of green algae (Chlorophyceae, Euglenophyceae, Conjugatophyceae), diatoms (Bacillariophyceae, Chrysophyceae, Dinophyta, Xanthophyceae), blue-green algae (Cyanophyceae) and cryptophyte algae (Cryptophyceae) [29].

\section{Statistical analysis}

Due to the limited number of test systems available, a regression design with three replicates for the control and five unreplicated test concentrations was used and the focus of the effect analysis was the calculation of $50 \%$ effect concentrations $\left(E_{50}\right)$ for reduction of abundance or emergence of potentially sensitive taxa, i.e. insects and gammarids. Regression analysis of mesocosm studies is less common than analysis of variance (ANOVA) to calculate no observed effect concentrations (NOECs) and lowest observed effect concentrations (LOECs), but it has been recommended in Liber et al. [30] and Azimonti et al. [31] and was also used for example in studies conducted in less than ten artificial streams or ponds by Mohr et al. [32] or Schäfers et al. [33]. Only taxa whose average abundance in the controls was higher than five, on at least two sampling occasions, were analysed using the three-parameter logistic regression model using ToxRat ${ }^{\circledR}$ (Version 3.2, ToxRat ${ }^{\circledR}$ Solutions GmbH).

To assess the suitability of the test systems for a mesocosm study meeting the requirements laid down by EFSA PPR [3], the minimum detectable differences (MDDs) for invertebrate taxa based on the data shortly before application (day -2) were estimated. For the MDD calculation we followed Brock et al. [34]: the abundance values were log transformed and then the mean and standard deviation were calculated. This standard deviation was used as an estimation of the pooled standard deviation and the MDD for the one-sided Williams test assuming a typical test design with five controls and five test concentrations with three replicates each was calculated. From this MDD related to the log-transformed data, the \% MDD for the original abundance scale were derived. The calculations are given in Additional file 4. In accordance with EFSA PPR [3], MDDs up to $70 \%$ were used, allowing to detect 'medium' effects, as suitable for a mesocosm study.

For analysing the effects on the macroinvertebrate and (emerged) insect community structure, principal response curves (PRC) were calculated [35, 36]. PRCs are based on the ordination technique constrained redundancy analysis, especially designed to display the effects of a single stressor on community structure over time using the following model:

$$
y_{\mathrm{d}(\mathrm{j}) \mathrm{tk}}=\bar{y}_{0 \mathrm{tk}}+b_{\mathrm{k}} c_{\mathrm{dt}}+\varepsilon_{\mathrm{d}(\mathrm{j}) \mathrm{tk}},
$$

where $y_{\mathrm{d}(j) t \mathrm{tk}}$ are the log-transformed abundances of taxon $k$ at time $t$ in treatment $\mathrm{d}$ and replicate $j, \bar{y}_{0 \text { tk }}$ is the log-transformed abundance of species $k$ at time $t$ in the control, $b_{\mathrm{k}}$ is the weight of species $k$ with PRC, $c_{\mathrm{dt}}$ is the principal response (canonical coefficient) of the community in treatment $\mathrm{d}$ on sampling date $\mathrm{t}$ and $\varepsilon_{\mathrm{d}(\mathrm{j}) \mathrm{tk}}$ is the error term for replicate $j$ of treatment on date $t$ for species $k$. Because high abundance values influence the result of the PRC more strongly than low abundance values and to achieve normal distribution of data, all abundances $(x)$ were log transformed using $\ln (2 x+1)$.

Results of the PRC analysis are shown in a diagram, where time is displayed on the $x$-axis and the canonical coefficient $\left(c_{\mathrm{dt}}\right)$ relative to the control (value: 0 ) on the $y$-axis. The more the $c_{\mathrm{dt}}$-values of treatments differ from the control line at point 0 , the more the community is influenced by the treatment. The species weights $b_{\mathrm{k}}$ are plotted in an additional diagram, which can be interpreted as the weighting of each single taxon for the principal response. The higher the species weighting, the more does the response pattern of the taxon follow the pattern in the PRC. Taxa with a high-magnitude negative value show a reversed pattern to the PRC. Taxa with species weightings between -0.5 and +0.5 show no or only a weak relation to the pattern of the PRC. Permutation tests allow calculation to determine whether the ordination can explain a significant proportion of the variance of the data set and whether the PRC diagram displays a significant part of the variance explained by the treatment. As follow-up analysis, redundancy analysis (RDA) with the log-transformed nominal concentration as the only environmental factor was conducted for each sampling date separately to test whether the treatment could explain a significant part of the variance of community structure on that day. The PRC and RDA analyses were performed with CANOCO 4.5 for Windows (Wageningen, NL). 


\section{Results}

\section{Chemical and physical characteristics of the water}

All eight individual stream mesocosms were similar in their physicochemical parameters throughout the study and showed no apparent trend in water parameters due to treatment levels (Additional file 1). However, the parameters showed considerable variability over time (e.g. temperature: $8.2-19.4{ }^{\circ} \mathrm{C}$; $\mathrm{pH}$ : 8.28-9.61; dissolved oxygen: $8.3-12.26 \mathrm{mg} \mathrm{O}_{2} / \mathrm{L}$ and conductivity: 217$489 \mu \mathrm{S} / \mathrm{cm}$ ). Likewise, nutritional parameters (ammonium, phosphate, nitrate) and water hardness were also similar between the stream mesocosms throughout the study (Additional file 1).

\section{Concentration of carbaryl in water}

The analytical method was successfully validated with mean recoveries of 106 and 107\% at the two fortification levels. The LOQ was set to be $0.15 \mu \mathrm{g}$ a.i./L (Additional file 2). One hour after application, $80-96 \%$ of the nominal carbaryl concentration could be found in the water samples proving the intended dosing of the stream mesocosm system (Fig. 2). Carbaryl concentrations in the stream water decreased exponentially with a mean dissipation half-time $\left(\mathrm{DT}_{50}\right)$ of $38.4 \mathrm{~h}$ (range 34.3-48.5 h). In the pooled control samples, carbaryl concentrations were always below the LOQ (Additional file 2).

\section{Macroinvertebrate abundance and taxa richness}

A total of 16,422 macroinvertebrate organisms were counted and differentiated into 51 taxa from all 80 samples during the study. The mean total number of macroinvertebrates of all eight systems directly before carbaryl application (sampling day -2) was 228 with a coefficient of variation (CV) of $22.8 \%$. The most dominant orders were Isopoda, Amphipoda, Hirudinea, Ephemeroptera and Trichoptera, each with more than 5\% of all individuals in the samples from two pre-sampling

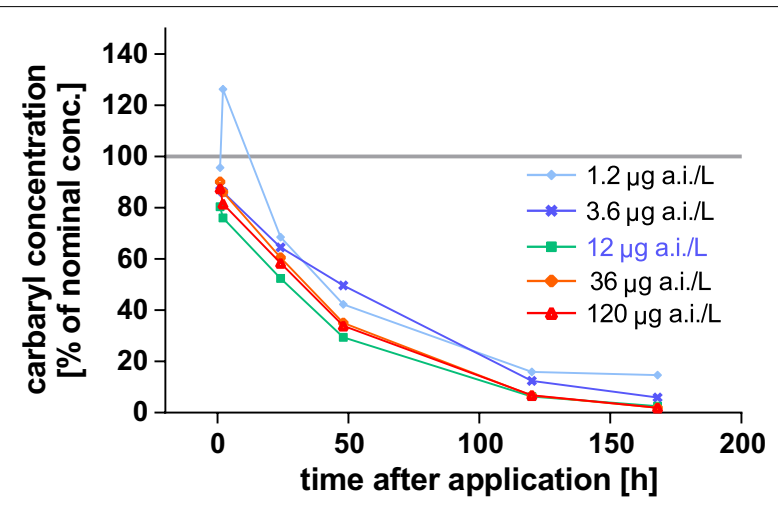

Fig. 2 Dissipation of carbaryl in the stream water dates and the control stream mesocosms after application (Fig. 3; Additional file 3). Overall, 29 arthropoda taxa represented more than $80 \%$ of all individuals, whereof $12.9 \%$ individuals from 15 taxa belonged to the group of EPT. Furthermore, 12 out of the 51 taxa found were characterised as SPEAR against pesticides. According to the SPEAR database, a considerable proportion of the taxa is characterised with a univoltine (29 taxa, 58\% of all taxa) or semivoltine (4 taxa, $8 \%$ ) life cycle and, thus, potentially vulnerable due to long generation times. The most dominant taxa were Asellus aquaticus (32.6\%), Gammarus sp. (27.7\%), Helobdella stagnalis (9.5\%) and the dipteran family Chironomidae (4.5\%). Also, organisms of the caddisfly family Limnephilidae, the mayfly species Ephemerella ignita and Ephemera danica, the leech Erpobdella octoculata and the flatworm Dugesia sp. were represented with more than $2 \%$ per taxa of total abundance.

Overall, 11 taxa fulfilled the criterion of more than five organisms on average in the control stream mesocosms on two sampling occasions and were analysed via logistic regression (Table 1). For 7 out of these 11 taxa, MDDs were estimated to be below $70 \%$ on sampling day -2 (Table 1, Additional file 4), suggesting that for these taxa effects would be detectable in a replicated test design with 20 test units. For the others, abundance before application was too low, but increased during the study.

During the study, 10-21 taxa were found per sampling date and the number of taxa showed no treatmentrelated trend (Fig. 4a). The total macroinvertebrate abundance ranged from 70 to 392 individuals per sample and was apparently affected by the treatment (Fig. 4b). In the highest carbaryl concentration of $120 \mu \mathrm{g} / \mathrm{L}$, the total number of individuals decreased from 198 to 91 individuals during the 1 st week following application, while the mean abundance of individuals in the control treatment was stable at around 200.

The principal response curve for the macroinvertebrate community shows small variation in the pre-treatment samplings and indicates long-term effects for the highest carbaryl concentrations and a short-term effect for $36 \mu \mathrm{g} / \mathrm{L}$ (Fig. 5a). The first canonical PRC axis is statistically significant (permutation test, $p=0.0240 ; 24.9 \%$ of the variance by treatment captured by the PRC), while the permutation test for all canonical axes did not show any statistical significance $(p=0.4960,41.8 \%$ of total variance explained by treatment, while $41.5 \%$ of total variance explained by time). Redundancy analysis and permutation tests per sampling date revealed a significant treatment effect on days $13(p=0.04), 36(p=0.016)$ and $57(p=0.002)$. Taxa with the highest correspondence to PRCs, indicated by high positive species weights, are the amphipod Gammarus sp., the mayfly E. danica and the alderfly Sialis lutaria (Fig. 5b). Other macroinvertebrate 


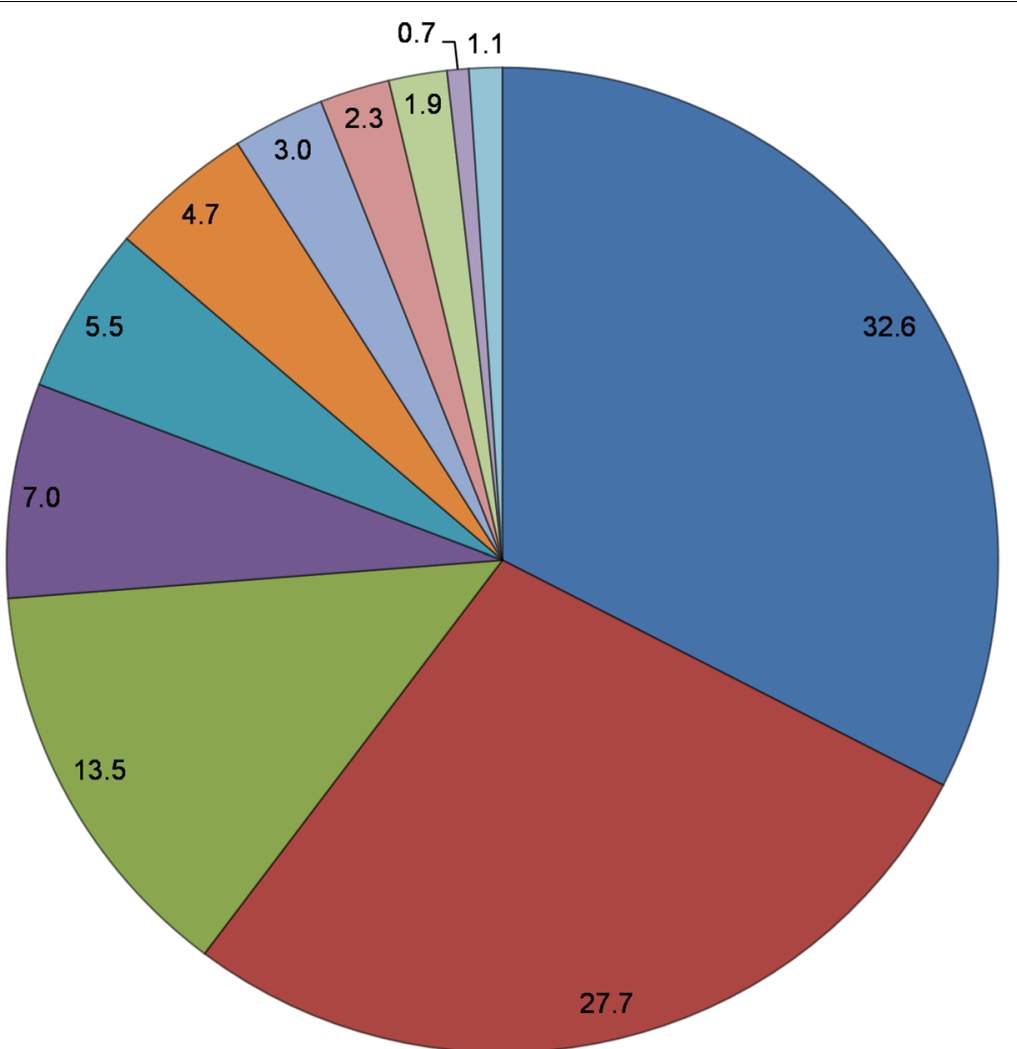

- Isopoda

$\square$ Amphipoda

$\square$ Hirudinea

घEphemeroptera

$\square$ Trichoptera

$\square$ Diptera

$\square$ Oligochaeta

$\square$ Tubellaria

$\square$ Megaloptera

$\square$ Gastropoda

$\square$ Bivalvia, Plecoptera, Odonata, Acari, Coleoptera

Fig. 3 Percentage composition of macroinvertebrate community of all eight stream mesocosms on pre-sampling days -21 and -2 and control stream mesocosms during the study time

taxa, such as Naididae, the caddisfly family Limnephilidae, Plecoptera n.d. and A. aquaticus, showed smaller species weights. The negative weights of the snails Radix sp., Radix ovata and Planorbis planorbis and the flatworm Dugesia sp. indicate an inverse response, i.e. an increase of abundance in the highest carbaryl treatment.

The population dynamics of the taxa with sufficiently high control abundance (>5) on at least two sampling dates are shown in Fig. 6. Most often, the response was not monotonous and did not allow the calculation of a reliable concentration response function, where a significant amount of variance is explained by the regression model. Nevertheless, the data indicate effects due to the higher carbaryl concentrations on a few species. The abundance of the amphipod Gammarus sp. decreased to zero immediately after application in the highest carbaryl treatment and did not recover until the end of the study (Fig. 6c). Abundance of Gammarus sp. was also reduced in the stream treated with $36 \mu \mathrm{g} / \mathrm{L}$ on the first sampling days after application. Also, the abundance of the caddisflies of the Limnephilidae family decreased in the highest carbaryl concentration on sampling days 6 and 13 after application (Fig. 6f). However, such a decrease was also observed at $3.6 \mu \mathrm{g} / \mathrm{L}$ and abundances of Limnephilidae decreased in general in all stream mesocosms including the control streams from day 21 until the end of the study down to near zero in all streams. Furthermore, the mayfly larvae $E$. danica showed a treatment-related trend of reduced population growth after application (Fig. 6d). While an average of 15 mayflies of this species were found in the controls at the end of the study on day 57 , only 2 individuals were found at $36 \mu \mathrm{g} / \mathrm{L}$ and none at $120 \mu \mathrm{g} / \mathrm{L}$ at the end of the study. However, variability in the control streams was large. No treatment-related trends were found for A. aquaticus, Chironomidae, Eiseniella tetraedra and others, except of a higher abundance of Dugesia sp. at the end of the study in the stream treated with $120 \mu \mathrm{g} / \mathrm{L}$.

\section{Invertebrate drift}

In total, 30 different taxa were found in the invertebrate drift samples. Thereby, ten taxa were characterised as organisms with a common and/or abundant drift behaviour, in accordance with Rico and van den Brink [7]. Invertebrate drift was clearly increased by factor four in the highest concentration during the $4 \mathrm{~h}$ following carbaryl application, above the level of the controls with respect to the total number of drifted organisms (Fig. 7a). 
Table 1 Taxa and combined subclasses/orders considered to be sufficiently abundant to assess the effects of the test item on at least two sampling dates (average control abundance $>5$ )

\begin{tabular}{|c|c|c|c|c|c|c|}
\hline Taxa & Order & $\begin{array}{l}\text { Sampling days } \\
\text { with mean } \\
\text { in control >5 }\end{array}$ & $\begin{array}{l}\text { Mean abundance } \\
\text { based on sampling } \\
\text { day }-2\end{array}$ & $\begin{array}{l}\text { MDD class (\%) } \\
\text { estimated based } \\
\text { on sampling day } \\
-2^{\mathbf{a}}, \mathbf{b}\end{array}$ & $\begin{array}{l}\text { Categorised } \\
\text { as species at risk } \\
\text { against pesticides } \\
\text { according to [28] }\end{array}$ & $\begin{array}{l}\text { Voltinism } \\
\text { according } \\
\text { to }[27,28]\end{array}$ \\
\hline \multicolumn{7}{|l|}{ Arthropoda } \\
\hline Asellus aquaticus & Isopoda & All sampling days & 70 & IV (28) & No SPEAR & Multivoltine \\
\hline $\begin{array}{l}\text { Chironomidae Gen. } \\
\text { sp. }\end{array}$ & Diptera & $-21,-2,6$ & 9 & IV (48) & No SPEAR & Multivoltine \\
\hline Gammarus sp. & Amphipoda & All sampling days & 69 & IV (36) & No SPEAR & Uni/bivoltine \\
\hline Ephemera danica & Ephemeroptera & $36,43,49,57$ & 0 & $-^{c}$ & No SPEAR & Semivoltine \\
\hline Ephemerella ignita & Ephemeroptera & $-21,-2$ & 9 & III (67) & No SPEAR & Univoltine \\
\hline $\begin{array}{l}\text { Limnephilidae Gen. } \\
\text { sp. }\end{array}$ & Trichoptera & $-21,-2,6,13,20$ & 12 & III (55) & SPEAR & Univoltine \\
\hline $\begin{array}{l}\text { Polycentropus fla- } \\
\text { vomaculatus }\end{array}$ & Trichoptera & $27,36,43,49$ & 0.2 & $0(202)$ & SPEAR & Univoltine \\
\hline \multicolumn{7}{|l|}{ Non-arthropoda } \\
\hline Dugesia sp. & Tricladida & $36,43,49,57$ & 4 & IV (48) & No SPEAR & Univoltine \\
\hline Eiseniella tetraedra & Crassiclitellata & $20,43,49$ & 0.2 & $0(209)$ & No SPEAR & Multivoltine \\
\hline Erpobdella octoculata & Arhynchobdellida & $43,49,57$ & 1 & $0(108)$ & No SPEAR & Univoltine \\
\hline Helobdella stagnalis & Hirudinida & $\begin{array}{c}-2,6,13,20,27,36 \\
43,49,57\end{array}$ & 21 & IV (43) & No SPEAR & Multivoltine \\
\hline \multicolumn{7}{|c|}{ Combined to higher subclass/order } \\
\hline Diptera & & $-21,-2,6$ & 10 & IV (45) & Not classified & Multivoltine \\
\hline Ephemeroptera & & $\begin{array}{c}-21,-2,6,13,36 \\
43,49,57\end{array}$ & 16 & IV (47) & SPEAR & Uni/bivoltine \\
\hline Trichoptera & & $\begin{array}{c}-21,-2,6,13,20 \\
27,36,43,49\end{array}$ & 12 & IV (49) & SPEAR & Univoltine \\
\hline Oligochaeta & & $6,13,20,27$ & 4 & $\|(71)$ & Not classified & \\
\hline Hirudinea & & All sampling days & 25 & IV (46) & No SPEAR & \\
\hline
\end{tabular}

a Re-transformed arithmetic mean of log-transformed data

b MDD classes according to the aquatic guidance document: $0=$ no effects can be determined (MDD $>100 \%) ; I=$ only large effects can be determined $(M D D=90-100 \%) ; I I=$ large to medium effects can be determined $(M D D=70-90 \%) ; I I=$ medium effects can be determined $(M D D=50-70 \%) ; I V=$ small effects can be determined $(\mathrm{MDD}<50 \%)$

c No E. danica was found in the stream mesocosms shortly before application
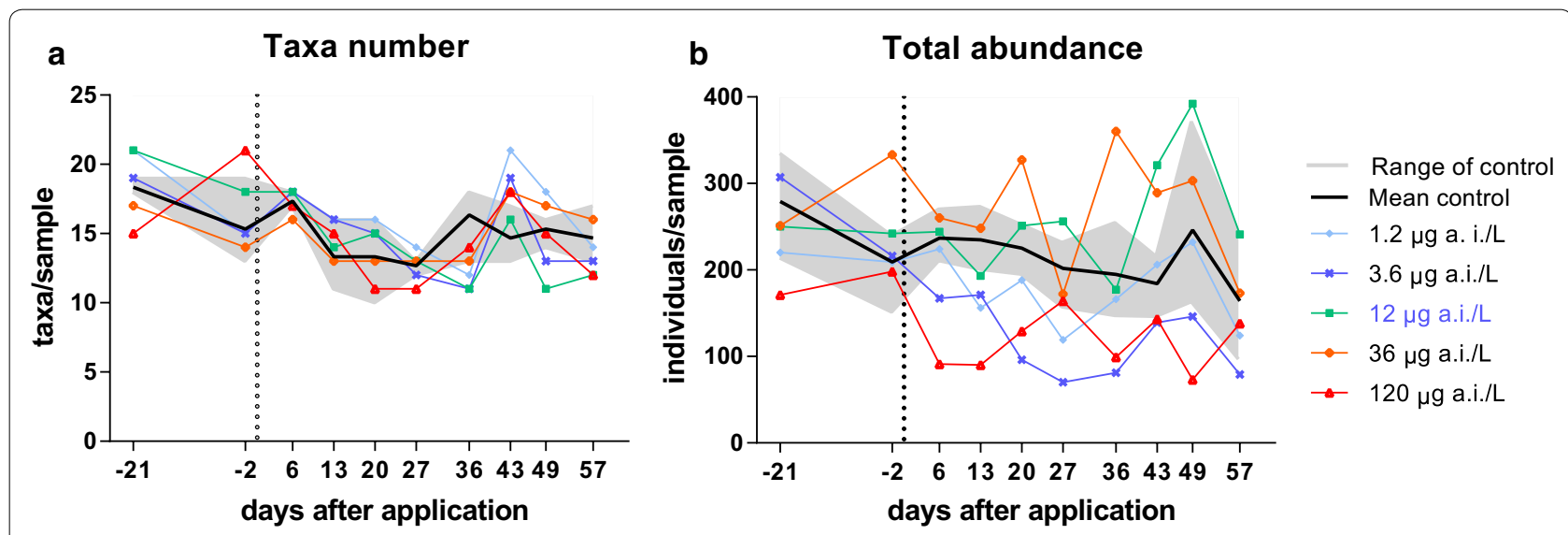

Fig. 4 Dynamics of a taxa richness and $\mathbf{b}$ total abundance of macroinvertebrates in the samples; dashed line: time point of application 

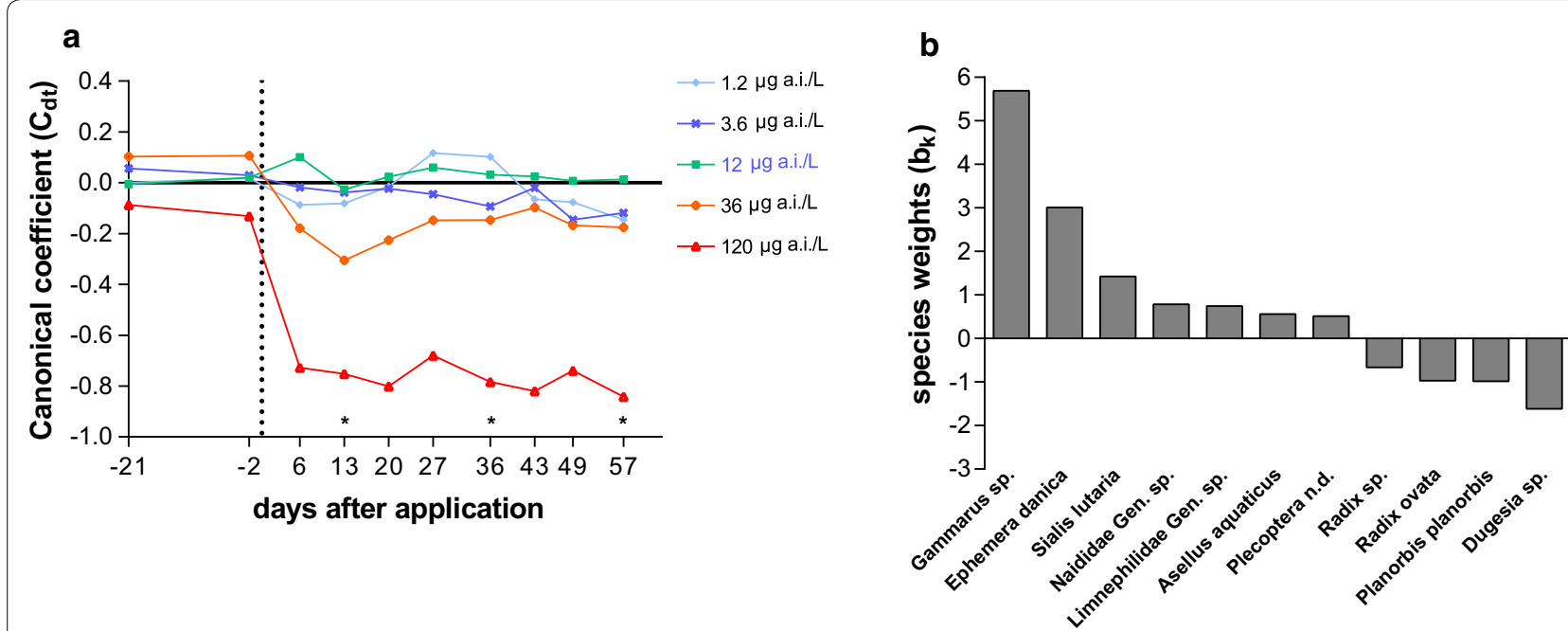

Fig. 5 Principal response curve of the macroinvertebrate community (a) and species weights (b) are only shown of $>+0.5$ or $<-0.5$. Asterisks indicate significant $(p<0.05)$ treatment effects according to RDA and followed by permutation test; dashed line: time point of application

Also, the number of taxa drifting was increased by more than factor two compared to the average of the control (Additional file 5). However, the higher drift numbers found at $120 \mu \mathrm{g} / \mathrm{L}$ were mainly caused by the planktonic Cladocera species Simocephalus vetulus (Fig. 7b). Also, after $8 \mathrm{~h}$ the number of $S$. vetulus increased in the highest carbaryl treatment (Additional file 5). Of the macroinvertebrates the amphipod Gammarus sp. was captured in the drift nets with more individuals in the highest carbaryl concentration (12 individuals) than in control (Mean: $<2$ individuals, Fig. $7 \mathrm{c}$ ) after $4 \mathrm{~h}$. In addition, drift of mayflies (especially E. ignita) increased $24 \mathrm{~h}$ after application (Fig. 7d). While the mean number in the control stream mesocosms was at 7 , the number in the carbaryl treatments ranged from 7 to 51 (Additional file 5). Hereby, a dose-dependent increase in drift was not observed.

\section{Emerging insects}

In the emergence traps, 11 taxa of the orders Diptera (especially Chironomidae), Ephemeroptera and Trichoptera were found. Three taxa fulfilled the criterion of more than five organisms on average in the control samples on two sampling occasions and were analysed with the regression model (Chironominae, Tanypodinae, Ephemeroptera). The mean taxa number in the control and also in the treated stream mesocosms decreased over time until the end of the study (Fig. 8a). Likewise total abundance of emerging insects decreased from more than 200 individuals per sample before application to less than 100 individuals until the end of the study (Fig. 8b). A potential treatment-related decrease in total emergence and number of taxa per sample was observed 7 days after application in the highest carbaryl concentration. However, no treatment-related effects were detected with nonlinear regression and the analysis of the community structure via PRC did also not indicate a significant treatment effect $(p=0.91)$.

\section{Periphyton}

The amount of periphyton, measured as the total chlorophyll a-concentration, ranged between 128.58 and $1283.40 \mu \mathrm{g} / \mathrm{m}^{2}$ and was dominated by green algae (Chlorophyta), with more than $38 \%$ of total sum per sampling day (Additional file 6). Four and 11 days after carbaryl application, the chlorophyll a content was increased by factor 1.2-2.4 (day 4) and 1.4-1.65 (day 11) in the treated stream mesocosms compared to the average of the controls (Additional file 6). By contrast, 26 and 33 days after carbaryl application chlorophyll a content in the two highest carbaryl concentrations was decreased by $46-66 \%$ in comparison to the average chlorophyll a content of the controls. However, there was no clear concentration response relationship and it was not possible to calculate reliable effect concentrations.

\section{Discussion}

\section{Establishment of a macroinvertebrate community representative for streams}

One aim of the study was to establish a macroinvertebrate community in the stream mesocosms with potentially sensitive and vulnerable species typical for lotic water bodies within an agricultural landscape. Therefore, the mesocosms were colonised by introducing 


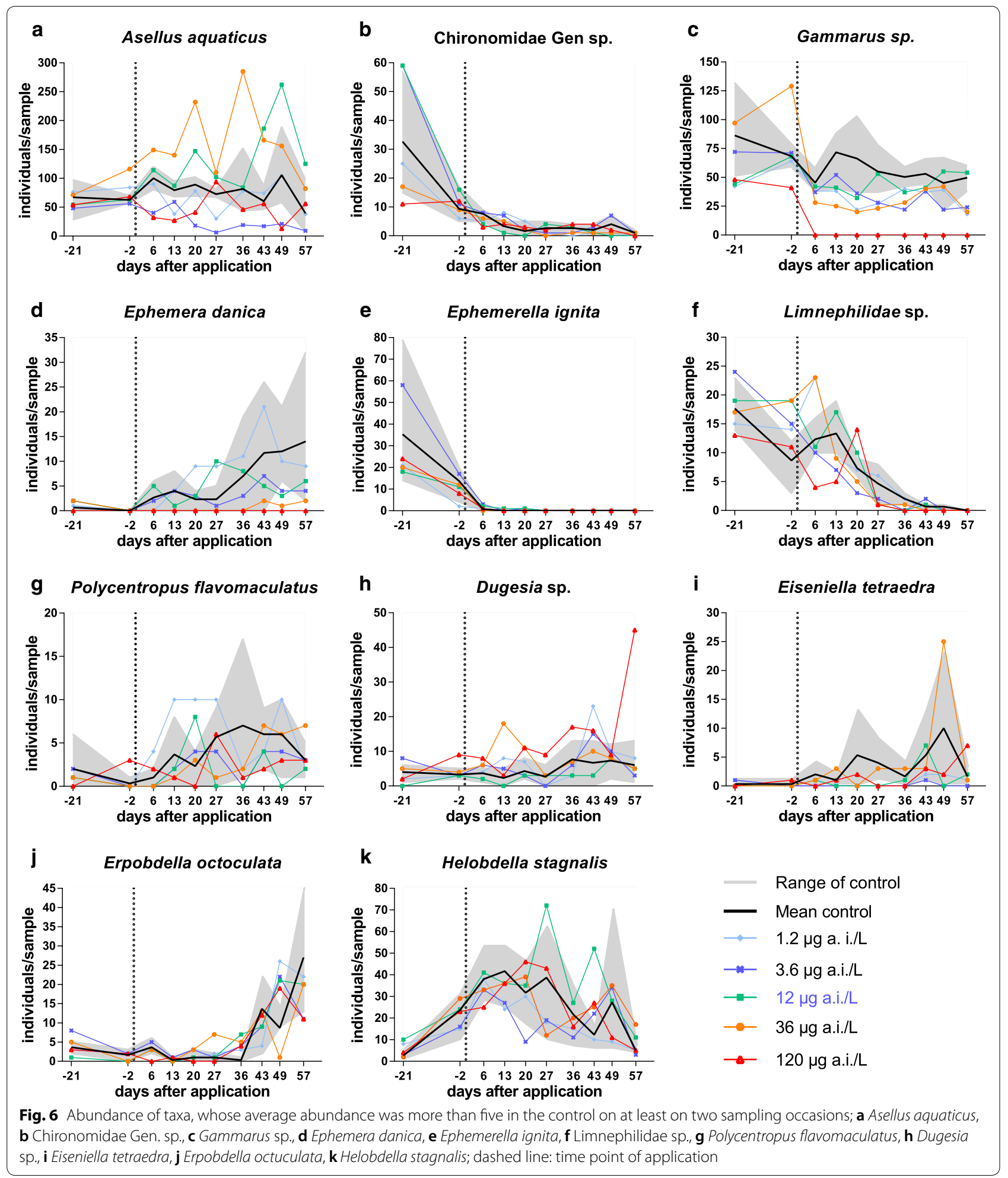

macroinvertebrates samplers which were exposed in two local streams. Arthropods are considered to be particularly sensitive to insecticides $[37,38]$ and therefore they are especially relevant for the effect assessment. In the present study, 29 taxa belonged to arthropods, which is quite similar to the number of taxa found in 

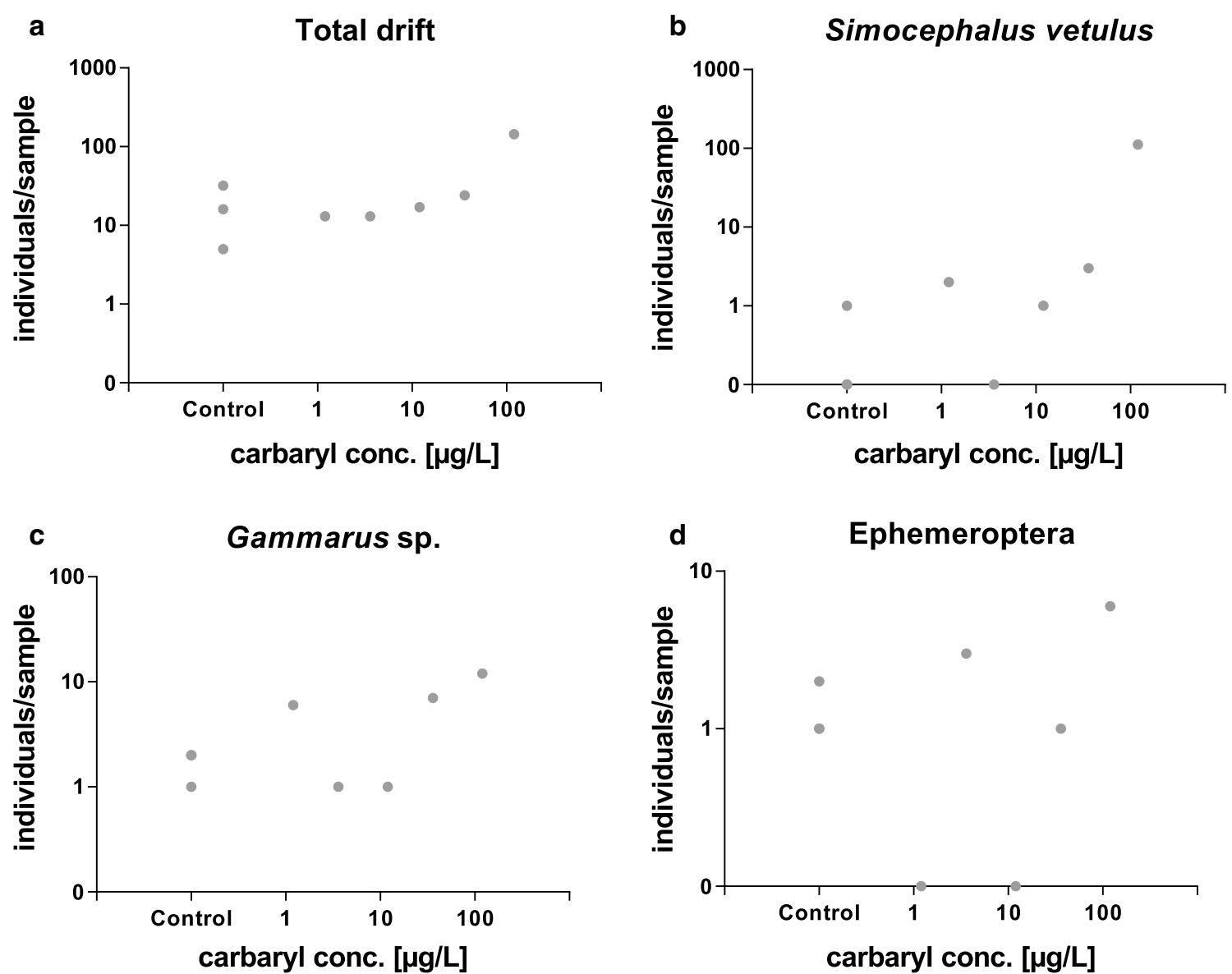

Fig. 7 Invertebrate drift at different carbaryl concentrations $4 \mathrm{~h}$ after application. a Total drift, b number of d Simocephalus vetulus, c Gammarus sp. and $\mathbf{d}$ the order Ephemeroptera
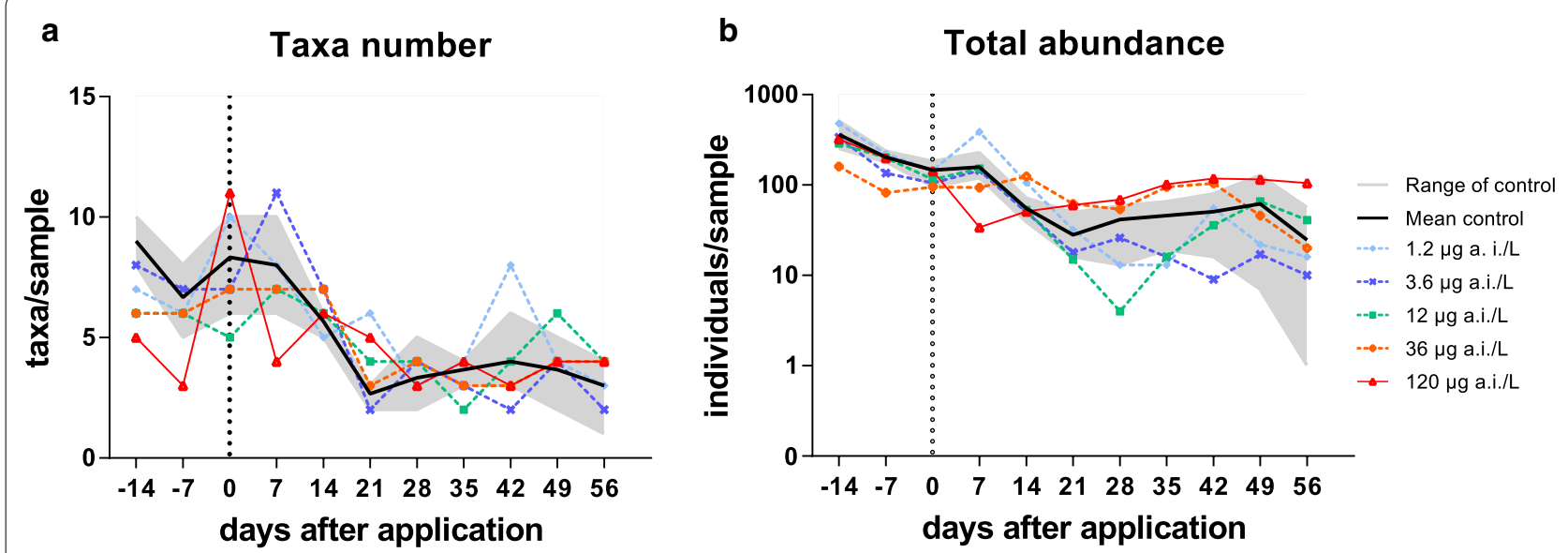

Fig. 8 a Number of taxa and $\mathbf{b}$ total abundance in emergence traps; dashed line: time point of application

small lotic streams within an agricultural landscape in Northern Germany (27 taxa) [24]. In addition, partly because of their long generation time, taxa of the orders
Ephemeroptera, Plecoptera and Trichoptera (EPT) are considered to be highly vulnerable towards insecticides and other stressors [7,39]. Similarly, the number of EPT 
taxa (15 taxa) corresponded to the mean EPT taxa number (13) of the investigated small streams in Wogram [24]. In terms of biological traits, aquatic macroinvertebrates often possess a univoltine life cycle. Furthermore, taxa with semivoltine life cycles, like many EPT taxa, should also be frequently presented as part of the macroinvertebrate community in an aquatic habitat and similarly in stream mesocosms. In this study, half of the detected taxa were univoltine, while a lower proportion had a semivoltine life cycle ( $8 \%)$. Thus, the number of taxa and the presence of different types of voltinism seem to be similar to what can be expected for real streams in the regional agricultural landscape.

\section{Taxa, which can be statistically analysed for effects}

However, as expected, a few taxa were dominant in the stream mesocosms and a lot of taxa were found only with low numbers. The EFSA Guidance Document requires that in mesocosm studies a reliable statistical analysis of effects should be possible for at least eight potentially sensitive populations and suggest reporting MDDs to evaluate this $[3,35]$. Due to the specific modes of action and confirmed by Maltby et al. [39], the Aquatic Guidance Document suggests arthropods (insects and crustaceans) as potentially sensitive taxa in an assessment of insecticides. Due to the limited number of the test systems and the selected regression design, no MDD analysis as for a typical replicated design [35] could be conducted in this study. Nevertheless, MDDs were estimated based on the variance of the eight mesocosms shortly before application. This analysis revealed MDDs below 70\%, thus allowing to detect small or medium effects [3], for five arthropoda (A. aquaticus, Gammarus sp., E. ignita, Limnephilidae n.d. and Chironomidae n.d.) and two nonarthropoda (Dugesia sp. and H. stagnalis) which might be relevant in case of, e.g. testing a fungicide with a non-specific mode of action. Four other species including a mayfly and a caddisfly were too rare before application, but were found in considerable numbers later which probably would have resulted in also sufficiently low MDDs. Six of the 11 taxa had a univoltine life cycle from which four taxa belonged to the order Ephemeroptera and Trichoptera and the other was a typical key taxon for lotic surface waters Gammarus sp. (uni- or bivoltine life cycle). The two caddisfly taxa are also defined as a 'Species at Risk for Pesticides' in accordance with Liess and von der Ohe [29]. However, based on voltinism, recolonisation potential and sensitivity to insecticides, it is not clear why the two mayfly species and Gammarus sp. are not considered SPEAR. Thus, by just increasing the number of test systems to allow a typical test design in accordance with the aquatic guidance document [3], probably seven arthropoda, considered potentially sensitive and some of them also vulnerable towards insecticides, and four nonarthropoda taxa could have been statistically analysed.

\section{Potential improvements}

Colonisation of the test systems by flying insects was possible since natural ponds, ditches and mesocosm ponds are in close proximity, but no typical streams are located nearby. Thus, typical stream species had to be introduced through macrophytes and substrates from undisturbed streams. For example, stonefly larvae (Plecoptera) were unfortunately too rare for a reliable evaluation in the stream mesocosms. Because stonefly larvae often live under stones in high-streaming habitats [40], the sampling technique for receiving macroinvertebrates from reference streams should be refined by searching for stoneflies directly under stones to increase the number of stoneflies introduced into the test systems. Conditions in the mesocosms, e.g. velocity and dissolved oxygen concentrations, seem to have been appropriate since no decline of numbers of sampled stoneflies was found from day -21 until day -2 .

In addition to increasing the number of introduced stoneflies and macroinvertebrates in general, improvement of the sampling techniques within the stream mesocosms during a study could be beneficial. For example, the food supply in the macroinvertebrate substrate sampler could be more diverse with different leaf types, which might enhance the presence of e.g. stoneflies. Enhancing the presence of macrophytes and submerged vegetation seems to be beneficial to provide a habitat for aquatic invertebrates $[42,43]$. Aquatic macrophytes serve not only as food source and substrate for periphyton, but are also frequently chosen as a substrate for oviposition of merolimnic insects [44]. Wieczorek et al. [11], for example, observed higher abundances of epiphytic Ephemeroptera species by providing high macrophyte densities and complex structures in stream mesocosms. Furthermore, next to the promotion of macrophyte vegetation in some sections of the stream mesocosms, providing more diverse substrates such as sediment, stones, wood and leaves could also increase diversity and abundance of taxa.

\section{Effects of carbaryl}

In the present study, a worst case exposure scenario was tested due to recirculation of water. This type of stream mesocosm study was also used in studies with insecticides, herbicides and heavy metals [41, 42] to examine the effects under worst case conditions. 
Carbaryl is a fast degrading toxicant and the calculated half-life of $38.3 \mathrm{~h}$ for dissolved carbaryl in all stream mesocosms is in accordance with previously conducted studies, where the half-life ranged between 40.0 and $139.2 \mathrm{~h}$ in river water [43-45]. The slightly alkaline water milieu (pH around 8.5 on the day of application) probably conditioned the fast dissipation observed [46-48]. This observation is in accordance with the studies of Aly and El-Dib where the half-life of carbaryl was $43.2 \mathrm{~h}$ at pH 8 [49]. To simulate more realistic, shorter exposure events expected in real streams, it is possible to replace part of the contaminated water through submersible pumps with uncontaminated water of similar quality and temperature.

In the present study, the PRC indicated toxic effects on the macroinvertebrate community in the highest carbaryl concentration $(120 \mu \mathrm{g} / \mathrm{L})$. Even if no significant logistic regression models could be fitted for the single taxa, the data suggest pronounced effects on the amphipod Gammarus sp. in the highest carbaryl concentration where the species could no longer be detected after day 6 (Fig. 6c). Also, at carbaryl concentrations of $36 \mu \mathrm{g} / \mathrm{L}$, the abundance of Gammarus sp. seemed to have been reduced over several sampling days after application. This is in line with various acute laboratory toxicity tests indicating $\mathrm{LC}_{50}$ values from 22 to $31 \mu \mathrm{g} / \mathrm{L}$ for Gammarus sp. $[13,50,51]$ considering the fast dissipation of carbaryl in the streams compared to the constant exposure over 4 days in the laboratory tests. Because Gammarus sp. became quasi extinct in the highest concentration, recovery would have only been possible under field conditions, e.g. by drift from uncontaminated upstream sections or other types of recolonisation.

Also, caddisflies of the Limnephilidae family showed a decrease in abundance in the first 2 weeks after application of the highest carbaryl concentration. $\mathrm{LC}_{50}$-values for larvae of quiver wearing caddisflies in $96 \mathrm{~h}$ laboratory tests ranged between 29 and $61 \mu \mathrm{g} / \mathrm{L}[18,22]$, which suggests that a carbaryl concentration of $120 \mu \mathrm{g} / \mathrm{L}$ could have indeed affected the caddisflies of the family Limnephilidae in the streams. In general, the abundances of Limnephilidae decreased in all stream mesocosms, including the controls, over time (Fig. 6f). It can be assumed that most of these caddisflies emerged during the first period of the study, which is in accordance with data from the emergence trap. Since the family Limnephilidae is widespread in Europe and a lot of species are considered to be species at risk $[28,52]$, it is advisable to assess the potential risk for this trichopteran family in higher-tier studies like lotic stream mesocosms. For improving the test systems regarding ecological risk assessment an earlier time point of application may result in longer dwelling times as caddisfly larvae and therefore the risk of pesticides in water can be assessed over a longer time period.

The abundances of the mayfly Ephemera danica reached relevant numbers only on the later sampling dates of the study (day 35-57), but apparently depended on the test concentration (Fig. 6d). No individuals were found in the stream treated with $120 \mu \mathrm{g} / \mathrm{L}$ during the whole study and at the end of the study, but also in the lowest test concentration the abundance was lower than per average in the controls. Thus, this mayfly is perhaps more sensitive than Gammarus sp. In laboratory studies with sediment, the $96 \mathrm{~h}-\mathrm{LC}_{50}$ of carbaryl for E. danica was $153 \mu \mathrm{g} / \mathrm{L}$ [13]. This result suggests no effects to be expected for $E$. danica in the lower carbaryl concentrations in this study. However, it is not clear if the dissipation was similar and which stages of larvae were tested. E. Danica is a semivoltine organism and the life cycle can last from 1 to 3 years. During the first sampling dates in July and August, the larvae of the newly hatched generation are very small, which makes it difficult to detect them during these months $[53,54]$. Younger organisms are usually more sensitive than older and larger organisms, for example because the higher surface to volume ratio results in higher uptake rates. Thus, effects on survival of the very young but sensitive larvae might have been overlooked in our study and became only visible when the survivors were larger and detected in the samples later in the study. Similar observations were also made in a stream mesocosm study by Beketov et al. [42] on long-term effects of the insecticide thiacloprid, where the stonefly larvae Nemoura cinerea and the mayfly larvae Ephemera vulgata were only found in control streams 27 weeks after application. Because of the fact that on every macroinvertebrate sampling day two stream biota A traps were removed from every stream mesocosm (with exception of stones and remaining leaf material), potential habitats for E. danica and other taxa were reduced and more concentrated on the remaining stream biota traps with every following sampling day. To avoid this possible issue, stream biota trap A should be placed back as a whole during the study.

The drift behaviour of aquatic invertebrates is crucial for the invertebrates themselves, as well as for the whole stream ecosystem [55]. Various types of disturbances like chemical contamination or abiotic and biotic factors (flow velocity, predation, competition) lead to downstream drift of macroinvertebrates [56]. In the present study, drift of the amphipod Gammarus sp. and the Cladoceran Simocephalus vetulus showed short-term increase (after $4 \mathrm{~h}$ ) for a carbaryl concentration of $120 \mu \mathrm{g} / \mathrm{L}$ (Fig. 7). The total number of organisms and taxa number increased with increasing carbaryl concentrations. This phenomenon was also observed by Beyers et al. or Courtemanch 
and Gibbs, immediately after carbaryl treatment in natural streams [20, 21]. Gammarus sp. and the Cladoceran Simocephalus vetulus, in particular, showed high drift in the highest carbaryl concentration (Fig. 7c). With the current sampling technique, it is not possible to determine whether both taxa were captured within the drift net because they were lethally affected or immobilised or whether they showed drift because of avoidance behaviour. In future studies, drift samples could be directly analysed for live/dead classification. However, in the case of Gammarus sp., lethal effects of the highest carbaryl concentration can be assumed based on the laboratory toxicity data and also the results from macroinvertebrate sampling (Fig. 6). Simocephalus vetulus is a common zooplankton organism, which normally lives in littoral zones of lakes and other basins, but can also be present in lotic systems $[57,58]$. Cladocera are one of the most sensitive orders to carbamates [59]. Acute single-species tests discovered that carbaryl is highly toxic to Daphnia magna (48 h EC $50: 5.6 \mu \mathrm{g} / \mathrm{L}$ ), which belongs to the same family as $S$. vetulus [23]. Therefore, it can be assumed that the increased numbers in drift samplers were caused by immobilisation or death. Visible effects of carbaryl were also observed in the drift numbers of mayflies $24 \mathrm{~h}$ after application. Possible mechanisms could be an increase in mortality, a knock-down effect or behavioural changes because of carbaryl [20]. Interestingly, these observations were not made already after $4 \mathrm{~h}$, indicating that it takes some hours before the internal concentration of carbaryl has reached a level to introduce drift. In other ecotoxicological studies the initiation of macroinvertebrate drift for several insecticides, mostly neurotoxic insecticides, was often potentially more sensitive than survival or immobilisation in acute toxicity $\left(\mathrm{LC}_{50}\right)$ tests in laboratory [60]. In another stream mesocosm study, drift behaviour was increased in insect larvae and gammarids after 12 -h pulses of imidacloprid, with investigators concluding that drift is a sensitive, relevant endpoint which should be considered in specific risk assessments for lotic surface waters [61].

In this study, carbaryl had no effects (in the sense of reliable dose response functions or on community level via PRC) on the emergence of insects. Only slight tendencies to impair the total emergence 7 days after application for $120 \mu \mathrm{g} / \mathrm{L}$ were found. Dominant emergent insects such as Chironominae, Tanypodinae and other Chironomidae, which dominated the numbers in the emerging traps, also did not show any effect on larvae abundances in the macroinvertebrate sampling, which confirms that these taxa were not affected by the treatment. Generally, emergence decreased over the course of the study. Spring and summer months are known for high emergence rates of merolimnic insects [62-64]. To cover the period of main emergence in a study, applications in further studies should be done earlier in the year than in this pilot study. This would probably allow a more powerful analysis of effects due to higher numbers of larvae in the test systems and imagines in the emergence traps.

Direct effects of carbaryl on the periphyton were not expected, but also indirect effects, e.g. promotion due to reduced grazing, were not found. This might be because the periphyton on the glass slides was not an attractive food source for the potentially affected taxa such as mayflies and caddisflies. In future studies, also the effects on leaf litter breakdown could be analysed to provide information on an important ecosystem function.

\section{Conclusions}

It could be demonstrated that stream mesocosms provide suitable habitats for potentially sensitive and vulnerable taxa representative for lotic systems such as gammarids, mayflies, caddisflies and stone flies. With more test systems than in this pilot study, e.g. 20 mesocosms for a replicated design, probably seven arthropoda and four non-arthropoda species would have allowed a statistical analysis of effects. To allow the analysis of further taxa, especially stoneflies, it is essential to increase the number of sampled organisms from sensitive and vulnerable taxa per stream mesocosm, for example, by (1) more targeted introduction by searching for organisms directly under stones and other substrates, (2) optimising the number and type of samplers in the mesocosms and (3) more passive introduction of macroinvertebrates through macrophytes and substrates from undisturbed streams. Due to circular flow, exposure duration in the streams is a worst case scenario compared to flow-through systems. However, by replacing water, faster dissipation can also be realised. Although the calculation of reliable $\mathrm{EC}_{50}$ values was often not possible, the study indicated the effects of carbaryl on the macroinvertebrate community and also on specific taxa (Gammarus sp., Limnephilidae, E. dan$i c a$ ), which were in line with available laboratory toxicity data.

\section{Additional files}

Additional file 1. Measurement of physical parameters during the study. Additional file 2. Recovery of carbaryl in stream mesocosms and results of method validation.

Additional file 3. List of macroinvertebrate taxa with dominance, voltinism and classification as Species at risk for Pesticides

Additional file 4. Calculation of minimum detectable difference on Day -2 abundance data.

Additional file 5. Raw data drift of invertebrates. 
Additional file 6. Total chlorophyll a value $\left[\mu \mathrm{g} / \mathrm{m}^{2}\right]$ and respective fractions [\%] of blue-greens (Cyaonprokaryota), greens (Chlorophyceae, Euglenophyceae, Conjugatophyceae, diatoms (Bacillariophyceae, Chrysophyceae, Dinophyta, Xanthophyceae) and Cryptophytes.

\section{Abbreviations}

a.i.: active ingredient; ANOVA: analysis of variance; CV: coefficient of variation; DF: delayed fluorescence; $\mathrm{DT}_{50}$ : 50\% dissipation time; ECx: effect concentration x; EFSA: European Food Safety Authority; EPT taxa: Ephemeroptera, Plecoptera, Trichoptera taxa; ERA: ecological risk assessment; ERO: ecological recovery option; $\mathrm{ESI}^{+}$: electrospray ionisation positive mode; ETO: ecological threshold option; $\mathrm{DT}_{50}$ : dissipation time 50\%; HPLC: high-performance liquid chromatography; $\mathrm{LC}_{50}: 50 \%$ lethal concentration; LOEC: lowest observed effect concentration; LOQ: limit of quantification; MDD: minimum detectable difference; MRM: multi-reaction monitoring; NOEC: no observed effect concentration; PRC: principal response curve; PPP: plant protection product; RDA:

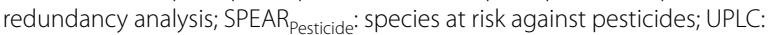
ultra performance liquid chromatography.

\section{Authors' contributions}

LKB and LD designed and performed experiments. KPE participated and supported with suggestions before and during the study. LKB analysed data and wrote the manuscript. UH, MK and CS conducted the analytical part of carbaryl and supported statistical analyses. All authors read and approved the final manuscript.

\section{Author details}

1 Department of Soil Science and Soil Conservation, Justus-Liebig University Gießen, Heinrich-Buff-Ring 26-32, 35392 Giessen, Germany. ${ }^{2}$ Institut für Gewässerschutz Mesocosm GmbH, Neu-Ulrichstein 5, 35315 Homberg (Ohm), Germany. ${ }^{3}$ Fraunhofer Institute for Molecular Biology and Applied Ecology IME, Auf dem Aberg 1, 57392 Schmallenberg, Germany. ${ }^{4}$ Present Address: RheinMain University of Applied Sciences, Am Brückweg 26, 65428 Rüsselsheim, Germany. ${ }^{5}$ Present Address: Department 2 Environmental Monitoring and Forensic Chemistry, Hamm-Lippstadt University of Applied Sciences, Marker Allee 76-78, 59063 Hamm, Germany.

\section{Acknowledgements}

The authors offer their thanks to Rabea Christmann and the whole Mesocosm $\mathrm{GmbH}$ team for their assistance with practical work and for their suggestions and critical discussions for improving the manuscript.

\section{Competing interests}

The authors declare that they have no competing interests.

\section{Availability of data and materials}

The authors declare that all data supporting the findings of this study are available in the article and its supplementary information files.

\section{Consent for publication}

Not applicable.

\section{Ethics approval and consent to participate}

Not applicable.

\section{Funding}

Not applicable.

\section{Publisher's Note}

Springer Nature remains neutral with regard to jurisdictional claims in published maps and institutional affiliations.

Received: 26 October 2018 Accepted: 4 January 2019

Published online: 24 January 2019

\section{References}

1. Commission Regulation (EU) (2013) No 283/2013 of 1 March 2013 setting out the data requirements for active substances, in accordance with the Regulation(EC) No 1107/2009 of the European Parliament and of the Council concerning the placing of plant protection products on the market

2. Commission Regulation (EU) (2013) No 284/2013 of 1 March 2013 setting out the data requirements for plant protection products, in accordance with the Regulation(EC) No 1107/2009 of the European Parliament and of the Council concerning the placing of plant protection products on the market

3. EFSA (2013) Guidance on tiered risk assessment for plant protection products for aquatic organisms in edge-of-field surface waters. EFSA J 11:3290. https://doi.org/10.2903/j.efsa.2013.3290

4. EFSA Scientific Committee (2016) Scientific opinion on recovery in environmental risk assessment at EFSA. EFSA J 14:4313. https://doi. org/10.2903/j.efsa.2016.4313

5. Gergs A, Classen S, Hommen U, Preuss TG (2011) Identification of realistic worst case aquatic macroinvertebrate species for prospective risk assessment using the trait concept. Environ Sci Pollut Res 18:1316-1323. https ://doi.org/10.1007/s11356-011-0484-6

6. Galic N, Baveco H, Hengeveld GM, Thorbek P, Bruns E, Van Den Brink PJ (2012) Simulating population recovery of an aquatic isopod: effects of timing of stress and landscape structure. Environ Pollut 163:91-99. https ://doi.org/10.1016/j.envpol.2011.12.024

7. Rico A, Van den Brink PJ (2015) Evaluating aquatic invertebrate vulnerability to insecticides based on intrinsic sensitivity, biological traits, and toxic mode of action. Environ Toxicol Chem 34:1907-1917. https://doi. org/10.1002/etc.3008

8. Brock TCM (2013) Priorities to improve the ecological risk assessment and management for pesticides in surface water. Integr Environ Assess Manag 9:64-74. https://doi.org/10.1002/ieam.1429

9. Brock TCM, Alix A, Brwon CD, Capri E, Gottenbüren BFF, Heimbach F, Lythgo CM, Schulz R, Streloke E (2010) Linking aquatic exposure and effects: Risk assessment of pesticides. SETAC. CRC, Boca Raton

10. Biggs J, Williams P, Whitfield M, Nicolet P, Brown C, Hollis J, Arnold D, Pepper $T$ (2007) The freshwater biota of British agricultural landscapes and their sensitivity to pesticides. Agric Ecosyst Environ 122:137-148. https:// doi.org/10.1016/j.agee.2006.11.013

11. Wieczorek MV, Bakanov N, Stang C, Bilancia D, Lagadic L, Bruns E, Schulz $R$ (2016) Reference scenarios for exposure to plant protection products and invertebrate communities in stream mesocosms. Sci Total Environ 545-546:308-319. https://doi.org/10.1016/j.scitotenv.2015.12.048

12. Hanazato T, Yasuno M (1987) Effects of a carbamate insecticide, carbaryl, on the summer phyto- and zooplankton communities in ponds. Environ Pollut 48:145-159. https://doi.org/10.1016/0269-7491(87)90093-5

13. Schäfers C (2012) Ecological approaches to aquatic ecotoxicology challenged by the needs of risk assessment. University Koblenz-Landau, Habilitation

14. Commission Decision 2007/355/EC of 21 May 2007 concerning the noninclusion of carbaryl in Annex I to Council directive 914/414/EEC and the withdrawal of authorisations for plant protection products containing that substance. Off J Eur Communities L131 2007:40-41

15. Gunasekara AS (2007) Environmental fate of carbaryl. Environmental Monitoring, Branch, Department of Pesticide Regulation. California. Environ Prot Agency, California

16. Seugé J, Bluzat R (1983) Chronic toxicity of three insecticides (carbaryl, fenthion and lindane) in the freshwater snail Lymnaea stagnalis. Hydrobiologia 106:65-72

17. Parsons JT, Surgeoner GA (1991) Effects of exposure time on the acute toxicities of permethrin, fenitrothion, carbaryl and carbofuran to mosquito larvae. Environ Toxicol Chem 10:1219-1227

18. Peterson JL, Jepson PC, Jenkins JJ (2001) A test system to evaluate the susceptibility of Oregon, USA, native stream invertebrates to triclopyr and carbaryl. Environ Toxicol Chem 20:2205-2214. https://doi. org/10.1897/1551-5028 
19. Toumi H, Burga-Perez KF, Ferard J-F (2016) Acute and chronic ecotoxicity of carbaryl with a battery of aquatic bioassays. J Environ Sci Heal Part B-Pesticides Food Contam Agric Wastes 51:57-62. https://doi. org/10.1080/03601234.2015.1080500

20. Beyers DW, Farmer MS, Sikoski PJ (1995) Effects of rangeland aerial application of Sevin-4-Oil ${ }^{\circledR}$ on fish and aquatic invertebrate drift in the Little Missouri River, North Dakota. Arch Environ Contam Toxicol 28:27-34. https://doi.org/10.1007/BF00213965

21. Courtemanch DL, Gibbs EK (1980) Short-and long-term effects of forest spraying of carbaryl (Sevin-4-oil ${ }^{\circledR}$ ) on stream invertebrates. Can Entom $112: 271-276$

22. Peterson $J \mathrm{~L}$ (2001) The use of native macroinvertebrates to assess pesticide risk to Oregon streams. Dissertation. Oregon State University

23. EFSA (2006) Final addendum to the Draft Assessment Report (DAR) carbaryl

24. Wogram J (2010) Ecological characterization of small streams in northern and central Germany. In: Brock TCM, Alix A, Brownet C, Göttesbüren BFF, Heimbach F, Lythgo CM, Schulz R, Streloke M (eds) Linking aquatic exposure and effects-risk assessment of pesticides. CRC Press, Societay of Environmental Toxicology and Chemistry (SETAC) Press, Pensacola, pp 250-268

25. PPDB (Pesticide properties database) (2018) Carbaryl (REF: UC 7744). https://sitem.herts.ac.uk/aeru/ppdb/en/Reports/115.htm. Accessed 29 Jan 2016

26. European Commission (2000) Residues: guidance for generating and reporting methods of analysis in support of pre-registration data requirements for Annex II (Part A, Section 4) and Annex III (Part A, Section 5) of Directive 91/414. SANCO/3029/99-rev.4, 11 July 2000

27. Liess M, Von Der Ohe PC (2005) Analyzing effects of pesticides on invertebrate communities in streams. Environ Toxicol Chem 24:954-965

28. Liess M, Von Der Ohe PC, Schriever CA, Schäfer RB, Beketov MA (2018) Online database of species at risk (SPEAR database). http://www.syste mecology.eu/spear/. Accessed 12 July 2018

29. Gerhardt V, Bodemer U (1998) Delayed fluorescence excitation spectroscopy: a method for automatic determination of phytoplankton composition of freshwaters and sediments (Interstitial) and of algal composition of benthos. Limnologica 28:313-322

30. Liber K, Kaushik NK, Solomon KR, Carey JH (1992) Experimental designs for aquatic mesocosm studies: a comparison of the anova and regression design for assessing the impact of tetrachlorophenol on zooplankton populations in limnocorrals. Environ Toxicol Chem 11:61-77. https://doi. org/10.1002/etc.5620110107

31. Azimonti G, Galimberti F, Marchetto F, Menaballi L, Ullucci S, Pellicioli F, Allessandra C, Lidia C, Allesio I, Angelo M, de Boer W, van der Voet H (2015) Comparison of NOEC values to EC10/EC20 values, including confidence intervals, in aquatic and terrestrial ecotoxicological risk assessment. EFSA Support Publ 12:906E

32. Mohr S, Schott J, Hoenemann L, Feibicke M (2015) Glyceria maxima as new test species for the EU risk assessment for herbicides : a microcosm study. Ecotox 24:309-320. https://doi.org/10.1007/s 10646-014-1379-3

33. Schäfers C, Klöppel H, Takahashi Y (2007) Zooplankton avoidance behavior following spray drift exposure to fenpyroximate. Humman Ecol Risk Assess 13:527-534

34. Brock TCM, Hammers-Wirtz M, Hommen U, Preuss TG, Ratte HT, Roessink I, Strauss T, Van den Brink PJ (2014) The minimum detectable difference (MDD) and the interpretation of treatment-related effects of pesticides in experimental ecosystems. Environ Sci Pollut Res 22:1160-1174. https:// doi.org/10.1007/s11356-014-3398-2

35. Van Den Brink Paul J, Ter Braak Cajo JF (1998) Multivariate analysis of stress in experimental ecosystems by principal responses curves and similarity analysis. Aquat Ecol 32:163-178. https://doi.org/10.1023/a:1009944004 756

36. Van den Brink PJ, Ter Braak CJF (1999) Principal response curves: analysis of time-dependent multivariate responses of biological community to stress. Environ Toxicol Chem 18:138-148. https://doi.org/10.1002/ etc. 5620180207
37. Brock TCM, Van Wijngaarden PPA, Van Geest GJ (2000) Ecological risk of pesticides in freshwater ecosystems. Part 2: insecticides. Alterra, Denver

38. Maltby L, Blake N, BrockTCM, Van den Brink PJ (2005) Insecticide species sensitivity distributions: importance of test species selection and relevance to aquatic ecosystems. Environ Toxicol Chem 24:379-388. https ://doi.org/10.1897/04-025R.1

39. Roy AH, Rosemond AD, Paul MJ, Leigh DS, Wallace JB (2003) Stream macroinvertebrate response to catchment urbanization (Georgia, U.S.A.). Freshw Biol 48:329-346

40. Fochetti R, Tierno De Figueroa JM (2008) Global diversity of stoneflies (Plecoptera; Insecta) in freshwater. Hydrobiologia 595:365-377. https:// doi.org/10.1007/s10750-007-9031-3

41. Mohr S, Berghahn R, Feibicke M, Meinecke S, Ottenströer T, Schmiedling I, Schmiediche R, Schmidt R (2007) Effects of the herbicide metazachlor on macrophytes and ecosystem function in freshwater pond and stream mesocosms. Aquat Toxicol 82:73-84. https://doi.org/10.1016/j.aquat ox.2007.02.001

42. Beketov MA, Schäfer RB, Marwitz A, Paschke A, Liess M (2008) Long-term stream invertebrate community alterations induced by the insecticide thiacloprid: effect concentrations and recovery dynamics. Sci Total Environ 405:96-108. https://doi.org/10.1016/j.scitotenv.2008.07.001

43. Liu D, Thomson K, Strachan WMJ (1981) Biodegradation of carbaryl in simulated aquatic environment. Bull Environ Contam Toxicol 27:412-417. https://doi.org/10.1007/BF01611041

44. Eichelberger JW, Lichtenberg JJ (1971) Persistence of pesticides in river water. Environ Sci Technol 5:541-544. https://doi.org/10.1021/es60053a002

45. Stanley JG, Trial JG (1980) Disappearance constants of carbaryl from streams contaminated by forest spraying. Bull Environ Contam Toxicol 25:771-776

46. Armbrust KL, Crosby DG (1991) Fate of carbaryl, 1-naphthol, and atrazine in seawater. Pac Sci 45:314-320

47. Fisher SW, Lohner TW (1986) Studies on the environmental fate of carbaryl as a function of $\mathrm{pH}$. Arch Environ Contam Toxicol 667:661-667

48. Wolfe NL, Zepp RG, Paris DF (1978) Carbaryl, propham and chlorpropham: a comparison of the rates of hydrolysis and photolysis with the rate of biolysis. Water Res 12:565-571. https://doi.org/10.1016/00431354(78)90134-3

49. Aly OM, El-Dib MA (1971) Studies on the persistence of some carbamate insecticides in the aquatic environment-I. Hydrolysis of sevin, baygon, pyrolan and dimetilan in waters. Water Res 5:1191-1205. https://doi. org/10.1016/0043-1354(71)90084-4

50. Sanders HO (1969) Toxicity of pesticides to the crustacean Gammarus lacustris. US Fish and Wildlife Service, Washington

51. SERA (Syracuse Environmental Research Associates I. (2008) CarbarylHuman Health and Ecological Risk Assessment Revised Final Report SERA Internal TR 52-01-05a

52. Kriska G (2013) Freshwater invertebrates in Central Europe. Springer, Wien

53. Svensson B (1977) Life cycle, energy fluctuations and sexual differentiation in Ephemera danica (Ephemeroptera), a stream-living mayfly. Nord Soc Oikos 29:78-86

54. Tokeshi M (1985) Life-cycle and production of the burrowing mayfly, Ephemera danica: a new method for estimating degree-days required for growth. J Anim Ecol 54:919-930

55. James ABW, Dewson ZS, Death RG (2008) The effect of experimental flow reductions on maroinvertebrate drift in natural and streamside channels. River Res Appl 24:22-35. https://doi.org/10.1002/rra

56. Brittain JE, Eikeland TJ (1988) Invertebrate drift-a review. Hydrobiologia 166:77-93. https://doi.org/10.1007/BF00017485

57. Amoros C (1984) Crustacés cladocères. Ectrait du Bull Mens la Société Linnéenne Lyon 5:1-63

58. Amoros C, Chessel D (1985) Populations of Cladocera (Crustacea), as describers of the hydrological functioning of stagnant waterways. Ann Limnol 21:227-240

59. Rubach MN, Baird DJ, Van Den Brink PJ (2010) A new method for ranking mode-specific sensitivity of freshwater arthropods to insecticides and its relationship to biological traits. Environ Toxicol Chem 29:476-487. https:// doi.org/10.1002/etc.55 
60. Beketov MA, Liess M (2008) Potential of 11 pesticides to initiate downstream drift of stream macroinvertebrates. Arch Environ Contam Toxicol 55:247-253. https://doi.org/10.1007/s00244-007-9104-3

61. Berghahn R, Mohr S, Hübner V, Schmiediche R, Schmiedling I, Svetich-Will E, Schmidt R (2012) Effects of repeated insecticide pulses on macroinvertebrate drift in indoor stream mesocosms. Aquat Toxicol 122-123:56-66. https://doi.org/10.1016/j.aquatox.2012.05.012

62. Corbet PS (1964) Temporal patterns of emergence in aquatic insects. Can Entomol 96:264-279
63. Füreder $L$, Wallinger $M$, Burger R (2005) Longitudinal and seasonal pattern of insect emergence in alpine streams. Aquat Ecol 39:67-78. https://doi. org/10.1007/s10452-004-2969-6

64. Caquet T, Hanson ML, Graham DW, Babin E, Azam D, Coutellec M-A, Knapp CW, Lagadic L, Caquet T (2007) Influence of isolation on the recovery of pond mesocosms from the application of an insecticide. I. Study design and planktonic community responses. Environ Toxicol Chem 26:1280-1290. https://doi.org/10.1897/06-250r.1

\section{Submit your manuscript to a SpringerOpen ${ }^{\circ}$ journal and benefit from:}

- Convenient online submission

- Rigorous peer review

- Open access: articles freely available online

- High visibility within the field

- Retaining the copyright to your article

Submit your next manuscript at $\boldsymbol{\nabla}$ springeropen.com 